\title{
Doenças Neurológicas nos Contos de Dalton Trevisan
}

\author{
Neurological Diseases in the Dalton Trevisan's Short Stories
}

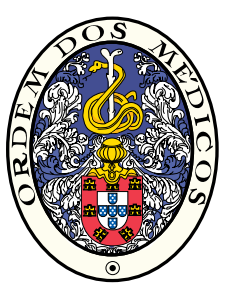

\author{
Hélio A. G. TEIVE ${ }^{1}$, Renato P. MUNHOZ ${ }^{1}$, Luciano de PAOLA ${ }^{1}$ \\ Acta Med Port 2014 Mar-Apr;27(2):232-235
}

\section{RESUMO}

Introdução: A relação entre a Literatura ficcional e a Medicina, em particular com a Neurologia, é bastante ampla. O objetivo desta revisão é de analisar a obra de Dalton Trevisan, considerado o mais importante escritor brasileiro de contos, com foco na descrição de enfermidades neurológicas nela contida.

Material e Métodos: Os autores avaliaram os livros de Dalton Trevisan que foram publicados desde 1959 até 2012.

Resultados: São apresentadas, de forma resumida, descrições de condições neurológicas frequentes, como epilepsia e doenças cerebrovasculares.

Discussão: Nesta revisão são abordadas várias doenças neurológicas, de grande prevalência na população em geral, como as epilepsias e as doenças cerebrovasculares, as quais são descritas de forma objetiva e prática pelo mestre brasileiro da narrativa curta.

Conclusão: O mundo ficcional do famoso contista brasileiro Dalton Trevisan está associado com inúmeros fatos do cotidiano, em particular o trágico-grotesco, e desta forma, as enfermidades neurológicas, particularmente as epilepsias e os quadros de acidente vascular encefálico, são referências que aparecem em sua obra.

Palavras-chave: Brasil; Doenças do Sistema Nervoso; Literatura Moderna; Medicina na Literatura; Pessoas Famosas.

\section{ABSTRACT}

Introduction: The relationship between fictional literature and Medicine, particularly Neurology, is very wide. The aim of this review is to analyze the Dalton Trevisan's work, considered the most important Brazilian short stories writer, focusing in the description of neurological diseases.

Material and Methods: A comprehensive evaluation of Dalton Trevisan's texts in books published between 1959 and 2012.

Results: Descriptions of the common neurological diseases embedded in Trevisan's work, such as, epilepsy and stroke, are presented. Discussion: This review disclosed neurological conditions highly prevalent in the general population, namely epilepsy and stroke, which have deserved a practical and objective approach by the Brazilian master of the short stories.

Conclusion: The fictional World of the famous Brazilian writer Dalton Trevisan is punctuated by everyday routine facts, which are however flavored with the tragic-grotesque touch so peculiar to the author. Neurological diseases, particularly epilepsy and stroke, are no exception to this universe and are exquisitely described by the writer.

Keywords: Brazil; Famous Persons; Literature, Modern; Medicine in Literature; Nervous System Diseases.

\section{INTRODUÇÃO}

A relação entre a Literatura ficcional e a Medicina, em particular com a Neurologia, é bastante ampla. ${ }^{1}$ Um grupo seleto de médicos é formado por escritores de grande renome e pode-se citar António Lobo Antunes, em Portugal, Anton Tchekhov na Rússia e João Guimarães Rosa, no Brasil. Na área neurológica, é bem conhecido o fato de que Silas Weir Mitchell, o fundador da Associação Neurológica Americana e seu primeiro presidente eleito, publicou 27 trabalhos ficcionais contendo referências neurológicas. ${ }^{2}$ Nos dias de hoje, Oliver Sacks é um exemplo vivo desta tendência, com publicações explorando a interface entre a literatura ficcional e a neurologia. De outra forma, existem vários escritores, não médicos, com trabalhos literários de ficção, com particular referência à área de Neurologia, como Shakespeare, Dostoievsky, Dickens e, no Brasil, Machado de Assis. ${ }^{1,3,4} \mathrm{O}$ objetivo desta revisão é de analisar a obra de Dalton Trevisan, considerado o mais importante escritor brasileiro de contos, com foco na descrição de enfermidades neurológicas nela contida.

\section{MATERIAL E MÉTODOS}

Os autores avaliaram os livros de Dalton Trevisan que foram publicados desde 1959 até 2012. As referências às doenças neurológicas foram registradas de forma resumida.

\section{RESULTADOS}

Nota Biográfica: Dalton J. Trevisan nasceu em Curitiba em 14 de junho de 1925, cidade onde vive até hoje. Formado pela faculdade de Direito da Universidade Federal do Paraná, trabalhou como advogado por pouco tempo, depois passou ao jornalismo, como repórter policial e como crítico de cinema. Na década de 40 editou a revista Joaquim, que foi a porta-voz de um grupo de intelectuais, reunindo ensaios de importantes escritores brasileiros da época. Publicou até agora 40 livros, 39 deles como contos e um único romance, intitulado 'A Polaquinha'. O seu livro de estreia foi 'Novelas nada exemplares' o qual o tornou conhecido nacionalmente. Dentre os seus livros mais conhecidos está 'O Vampiro de Curitiba', com inúmeras edições

1. Serviço de Neurologia. Departamento de Medicina Interna. Hospital de Clínicas. Universidade Federal do Paraná. Curitiba. Brasil. Recebido: 21 de Abril de 2013 - Aceite: 22 de Julho de 2013 | Copyright @ Ordem dos Médicos 2014 
no Brasil e em todo o mundo. Ao longo de sua profícua carreira, o autor recebeu inúmeros prémios, incluindo o prémio Ministério da Cultura de Literatura, o Jabuti, e em anos mais recentes o prémio Portugal Telecom de Literatura, este por duas vezes. No Brasil, foi agraciado no ano de 2012 com o prémio Machado de Assis, da Academia Brasileira de Letras. No mesmo ano, em Portugal, recebeu também o prémio Camões, considerado o maior prémio literário de língua portuguesa, destinado a premiar um autor pelo conjunto da sua obra. ${ }^{5-7}$

\section{Dalton Trevisan e a Neurologia}

Foram avaliados 37 livros de contos, incluindo coleções de contos escolhidos e uma novela. Do total de livros analisados, mais de $50 \%$ deles contêm referências a problemas relacionados com a medicina interna, principalmente doenças cardíacas, pulmonares, mas também doenças psiquiátricas. Referências a doenças neurológicas foram encontradas em oito livros $(21,6 \%)$, particularmente na área de epilepsia e doenças cerebrovasculares, ainda que não exclusivamente.

\section{Epilepsia}

Trevisan apresenta em alguns dos seus contos referências gerais a pessoas com epilepsia, bem como casos de epilepsia per si, com descrição da clássica crise epiléptica generalizada tónico-clónica em paciente com possível meningo-encefalite, que vai a êxito letal, e outro caso de paciente com retardo mental e paralisia cerebral, com epilepsia secundária. Por vezes, em alguns contos, apresenta descrições vagas de personagens com 'ausência' (em possível alusão a crises epilépticas do tipo parciais complexas).

No conto intitulado 'Que fim levou o vampiro louco de Curitiba?' (publicado no livro 'O Pássaro de cinco asas'), aparece uma referência geral a pessoas com epilepsia:

“(...) Os famosos epilépticos que fim levaram! - ah, todas as ruas eram povoadas de epilépticos! - com seu grito lancinante, quem ouviu nunca mais esquece, sua borbulha na língua mordida, sua pocinha de água na calçada?" 8

No conto 'Pedrinho' (do livro 'Novelas nada exemplares'), existe uma descrição precisa de uma criança que vai a óbito por provável meningo-encefalite não tratada. $A$ criança queixa-se de cefaléia, depois febre e fica inapetente, com fotofobia, e foi levada para avaliação. ${ }^{9}$

“(..) - Não é nada - disse o farmacêutico. - É gripe." Com a piora do quadro, a mãe recorre ao farmacêutico. “(...) Seu Juca, não acha que pode ser.... - Que esperança, dona! Ergueu com cuidado a cabeça do menino. - Ele gemeu? - Não. - A senhora viu. Se fosse aquela doença, gritava de dor."

Na sequência, "(...)Tornando do emprego, o pai viu da esquina os vizinhos diante da casa. - Que demorou tanto, homem de Deus? A mulher chorava de pé, a cabeça apoiada na parede. Uma vizinha esfregava vinagre nos pulsos do menino desmaiado. Debruçou-se o pai na cama - a criança virou o branco do olho. - Pedrinho. Pedrinho. Ri-
Ihava os dentes que nem ataque de bichas. Roxo de tanto se retorcer, o corpo em arco da nuca ao calcanhar. Depois de cada convulsão fechava penosamente o olho."

"(...) com sede, o piá ("menino pequeno") estalava os lábios. A gemer, não deixou que Ihe inclinassem a cabeça, rolando no travesseiro". "(...)Súbito um pulo na cama. $A$ mãe foi erguer-Ihe a cabeça e Pedrinho gritou. De noite, a criança de olho perdido na lâmpada". "(...) Rígido na cama, olho preso na lâmpada". "(...) a mãe rezava de joelho ao lado da cama. Pedrinho de olho parado. Ela soltou um grito: - Morreu.... Meu filhinho morreu! - Não chore, mulher. Sou o pai, não estou chorando." 9

No conto 'Ó doce cantiga de ninar' (do livro o 'Pássaro de cinco asas'), existe a descrição de um médico que vai atender a um paciente, filho de sua vizinha, com retardo mental grave e paralisia cerebral, após uma crise epiléptica generalizada tónico-clónica ${ }^{8}$ :

“(...) - O doutor desculpe. Não sei a quem apelar - e afastou-se, revelando o quadro. Na cadeira um bicho medonho. Barbudo, guincha e sacode-se de fúria”. "(...) Corpo de menino e cabeça de velho, grisalho, dente podre. No pijama gota de café, borrifo de sopa, buraco de cigarro. Perna fininha e curta, no pé inútil a longa unha recurva. Além de paralítico, retardado - aos dezoito anos rosna duas ou três palavras: manhê, papinha, dodói. Borbulha a boca torta do monstrinho, a dona queixa-se para João e, puxandoIhe a manga, a moça funga nervosa. Interná-lo, a mãe não podia, muito caro o tratamento. Como indigente ninguém o aceita." "(...)Cabeça caída no peito, parece adormecido. O doutor arrisca um passo. Espirra olho vermelho de sapo debaixo da pedra. Dentes amarelos arreganham-se: corre a mão no queixo, respinga fios de escuma. - Acha que a baba pega! ${ }^{8}$

No conto 'A gordinha sagrada' (publicado no livro 'Abismo de Rosas'), existe a descrição de crises epilépticas pela própria protagonista, durante um encontro amoroso. ${ }^{10}$ “- Veja o exame. Não deu nada. Sugere-se repetição do eletro em sono barbitúrico. Na bolsa vermelha lenço de papel, espelhinho redondo, batom, vidro de comprimido, lápis até uma rolha. - Para não morder, você sabe. A língua." "- Pode vir de repente? - Se tomo remédio não tem perigo. Contei que meu noivo quer desmanchar?” "- Desde quando? - O primeiro com treze anos. No colégio uma gritaria de incêndio. Todas correndo. Em pânico eu tive uma coisa. Fiquei roxa e babei muito. Só voltei em casa. - Não sente aura? - Debaixo de bolinha. Quatro anos sem ter. Agora de novo. Basta que me incomode. Seja contrariada. - Como é que foi? Um na Rua Emiliano. Caí na calçada. Duas coleguinhas me acudiram. Chamaram a ambulância. Acordei no pronto-socorro." "- Outro foi no baile. Dançava com meu noivo. De repente saí de mim." "- Em pleno salão, já imaginou? A vergonha é a pocinha d'agua.” " - Um grito que eu ouço mesmo dormindo. - Sente o quê? - Não ter uma pessoa perto. Que não me deixe cair. Sabe que já não me bato? -Ainda baba? - Sim. Fico dormindo até o dia seguinte". 10

No conto 'A segunda mulher' (publicado no livro 'Essas 
malditas mulheres'), há uma curta descrição de possível crise epiléptica parcial complexa. ${ }^{11}$

"(...)- Foi internado quando guarda-civil? - Dos nervos, o senhor sabe. Lá no asilo Nossa Senhora da Luz. Um par de vezes. A segunda que me internou e me aposentou. Crise de ausência, dizia o doutor Alô. Eu me retiro de mim mesmo. Como choque elétrico depois eu volto". ${ }^{11}$

Da mesma forma são apresentados casos de eventos não epilépticos em mulheres, com descrições de síncopes (relacionadas a eventos estressantes) e de possíveis transtornos somatoformes, sob forma de crises conversivas (histeria).

No conto 'Tentações de uma pobre senhora' (do livro 'Guerra Conjugal'), existe uma descrição de adultério, em que o Sr. João, junto com a polícia, encontra a esposa, Sra. Maria, em um quarto de hotel, com o amante. A esposa apresenta rascunhos de cartas explicando o motivo do adultério. ${ }^{12}$

“(..) Eram rascunhos, desculpou-se Maria, a exibir a coxa muito grossa, rabiscados em momento de desvario e, olho branco, sofreu um ataque. O porteiro acudiu com água e açúcar. Tornado a si, a pobre senhora bebeu alguns goles e perguntou se mais devedor não era o marido que, ao negar-lhe o carinho, a humilhava no seu orgulho de mulher". ${ }^{12}$

\section{Doenças Cerebrovasculares}

Nos livros de Dalton Trevisan, as referências às doenças cerebrovasculares foram feitas de duas formas. Em primeiro lugar, menções aos ataques isquémicos transitórios e depois ao acidente vascular encefálico, provavelmente isquémico, no hemisfério cerebral direito, com sequela neurológica motora.

No conto 'A segunda mulher' (publicado no livro 'Essas malditas mulheres'), há referência a um provável ataque isquémico transitório. ${ }^{11}$

“(..) Aposentado por motivo de saúde? - Não pense que tenho veia rebentada. A cabeça está sã, inteirinha. Só este ano um ameaço de derrame. - Bobagem, José. - Fui pegar a caneca - e ela caiu. Quis abrir a porta - e o trinco não virou. Daí me sentei. Que é isso, minha mão? - Ainda bem que respondeu". ${ }^{11}$

No conto intitulado 'Um passeio no inferno' (publicado no livro 'O Grande deflorador'), o autor descreve ${ }^{13}$ :

“(...) Depois de um sono agitado foi se virar: o braço esquerdo inútil. Quis levantar - a perna esquecida. Ao chamar pelo traste da velha, gorgolejou ronco feito. Credo João. De joelho e mão posta - bem como ele implicava. - Está meia boca. Em coma três dias e três noites. $-E$ quando voltou a idéia? (...)Cinco dias depois o genro lhe corta o cabelo e faz a barba. - Já está melhor. Mas não repare. Ainda com meia boca. - Sorte, não afetou a fala. No corredor é prevenido o amigo. - Só não fale em derrame. Que ele não sabe. (...) Sentadinho na cadeira de braço. Lenço branco no pescoço, bombacha cinza listada, bota preta. Ao ombro a capa azul de forro escarlate de rei dos tropeiros. - Foi um mau jeito. Agora eu descobri. Do maldito vento encanado - essa veIha com a mania da porta aberta." ${ }^{13}$

\section{Outras doenças neurológicas}

$\mathrm{Na}$ obra de Trevisan, existem breves referências às cefaléias do tipo migraine (enxaqueca), particularmente, quanto aos fatores desencadeantes de crises, em especial, as situações de estresse.

No conto 'A grande fiteira' (publicado no livro 'O Rei da Terra'), há uma brevíssima referência a situação acima referida, no estilo Hai Kai. ${ }^{14}$

\section{"(...)A enxaqueca de Maria tem o nome João". ${ }^{14}$}

Da mesma forma que em relação às cefaléias, encontra-se na obra de Trevisan referências a pacientes com disfunção cognitiva, e a demência. No conto 'Cinco Haicais' (publicado no livro 'Em busca de Curitiba perdida'), Trevisan escreve ${ }^{15}$ :

"(...)Na hora de assinar, todo soberbo o velhote, no seu oclinho torto: - O meu nome, qual é? Quem mesmo sou eu?"'5 Ou ainda, no conto 'O Nome do jogo' (publicado no livro 'Essas malditas mulheres')

"(...) Na hora de assinar, o velhinho muito fraco, com aquele óculo torto: Como é meu nome? Quem sou eu mesmo?'11

Trevisan faz referência em seus contos a pacientes acometidos de paraplegia crural, decorrente de mielopatia compressiva, com descrição associada de bexiga neurogénica e de escaras de decúbito. No conto 'Eis a primavera' (publicado no livro 'O Rei da Terra'), há um relato de um paciente com paraplegia crural secundária a metástase na coluna vertebral. ${ }^{14}$

“(...) João saiu do hospital para morrer em casa - e gritou três meses antes de morrer. Para não gastar, a mulher nem uma vez chamou o médico." "(...)Já não tinha posição na cama: as costas uma ferida só. Paralisado da cintura para baixo, obrava-se sem querer. A filha tapava o nariz com dois dedos e fugia para o quintal: Ai que fedor... Meu Deus, que nojo!'”4

\section{DISCUSSÃO}

O escritor Dalton Trevisan, famoso por seus contos, alguns definidos como minicontos, como um haicai, reconhecidos nacional e internacionalmente, tem um estilo inconfundível, em que se sobressaem a narrativa objetiva, singular, com síntese da linguagem, com uso constante da elipse, apresentando um estilo meticuloso, denso e obsessivo. Existe uma concisão extrema da linguagem, que aliada à conhecida reclusão do escritor, ajudou a formar o mito do 'vampiro de Curitiba', o qual é o título do seu livro mais famoso. O escritor tem um senso dramático da condição humana, que, aliás, está inerente à pratica clínica neurológica. Nesta revisão histórica, são abordadas várias doenças neurológicas, de grande prevalência na população em geral, como as epilepsias e as doenças cerebrovasculares, as quais são descritas de forma objetiva e prática pelo mestre da narrativa curta. São apresentados casos de epilepsia, com descrição de crises epilépticas do tipo generalizadas tónico-clónicas e possíveis crises parciais complexas, bem como casos com eventos paroxísticos não epilépticos de origem fisiológica, como as síncopes e a transtornos so- 
matoformes, possíveis crises conversivas (histeria), agora definidas como funcionais. Da mesma forma, são apresentados casos com acidente vascular encefálico, do tipo isquêmico e mesmo ataques isquémicos transitórios. Outras doenças neurológicas são apresentadas, sempre com descrições bem detalhadas que se enquadram perfeitamente com a anamnese neurológica usual. Trevisan, reconhecido misantropo, é um observador atento dos pormenores da realidade, característica inerente aos grandes escritores. Ele tem uma aguda consciência do real, e desta forma, o mundo ficcional do famoso contista brasileiro está associado com inúmeros fatos do cotidiano, em particular o trágico-grotesco, e desta forma, as enfermidades neurológicas, particularmente as epilepsias e os quadros de acidente vascular encefálico, são referências que aparecem em sua obra, contudo sem ser de forma expressiva. Em uma das poucas entrevistas que o escritor Curitibano deu a impressa, no ano de 1969, ele sugeriu, de forma resumida, o seu modus operandi: "O escritor é uma pessoa que não merece confiança. Um amigo chega e me conta as maiores dores; eu escuto com atenção, mas estou é recolhendo material para mais um conto. E eu sei disso na hora. Surge então a má consciência. Sei que estou fazendo assim e não de-

\section{REFERÊNCIAS}

1. Iniesta I. Neurology and literature. Neurologia. 2010;25:507-14.

2. Louis ED, Horn S, Roth LA. The neurologic content of S. Weir Mitchell's fiction. Neurology. 2006;66:403-7.

3. Iniesta I. Neurologia y Literatura 2. Neurologia. 2011 [in press].

4. Teive HA, De Paola L, Cardoso F. A neuropsiquiatria em Machado de Assis. Acta Med Port. 2007;20:385-92.

5. e-biografias. Dalton Trevisam escritor brasileiro. [Consultado 2013 Feb 02] Disponível em: http://www.e-biografias.net/dalton_trevisan/.

6. Rocha JC. Quem tem medo de Dalton Trevisan. J Estado São Paulo. 2012.

7. Silva M. Dalton fala de Machado. Caderno G. J Gazeta Povo. 2013.

8. Trevisan D. O Pássaro de cinco asas. A Trombeta do anjo vingador. São Paulo: Círculo do Livro; 2012. sejaria fazer, mas não há outro jeito. O escritor é um ser maldito". ${ }^{16}$

O estilo peculiar de Dalton Trevisan, que aparece de forma tão evidente na descrição das enfermidades neurológicas aqui descritas, pode ser decorrente de inúmeros fatores, incluindo fatores pessoais (tipo de personalidade), aliada a fatores ambientais (tragédias familiares).

De uma forma geral, pode-se dizer que a narrativa de Dalton Trevisan vai de encontro com a medicina baseada na narrativa (narrativa do paciente), que deve estar associada com o paradigma atual da medicina baseada em evidências. ${ }^{3}$

\section{AGRADECIMENTOS}

A Raul Munhoz Neto pela revisão ortográfica e gramatical do texto.

\section{CONFLITOS DE INTERESSE}

Não há conflitos de interesse para declarar.

\section{FONTES DE FINANCIAMENTO}

Os autores não mencionam quaisquer fontes financiamento.

9. Trevisan D. Novelas nada exemplares. Rio de Janeiro: Editora Record; 1979.

10. Trevisan D. Abismo de rosas. Rio de Janeiro; Editora Record; 2003.

11. Trevisan D. Essas malditas mulheres. Rio de Janeiro: Editora Record; 1982.

12. Trevisan D. Guerra conjugal. Rio de Janeiro: Editora Record; 2006.

13. Trevisan D. O grande deflorador. Porto Alegre: Editora L\&PM; 2000.

14. Trevisan D. O Rei da Terra. Rio de Janeiro: Editora Record; 2007.

15. Trevisan D. Em busca de Curitiba perdida. Rio de Janeiro: Editora Record; 2004.

16. Andrioli L. O silêncio do vampiro. O discurso jornalístico sobre Dalton Trevisan. São Paulo: Editora Kafka; 2013. 


\section{Doenças Neurológicas nos Contos de Dalton Trevisan}

Acta Med Port 2014:27:232-235

Publicado pela Acta Médica Portuguesa, a Revista Científica da Ordem dos Médicos

Av. Almirante Gago Coutinho, 151

1749-084 Lisboa, Portugal.

Tel: +351 218428215

E-mail: submissao@actamedicaportuguesa.com

www.actamedicaportuguesa.com

ISSN:0870-399X | e-ISSN: 1646-0758

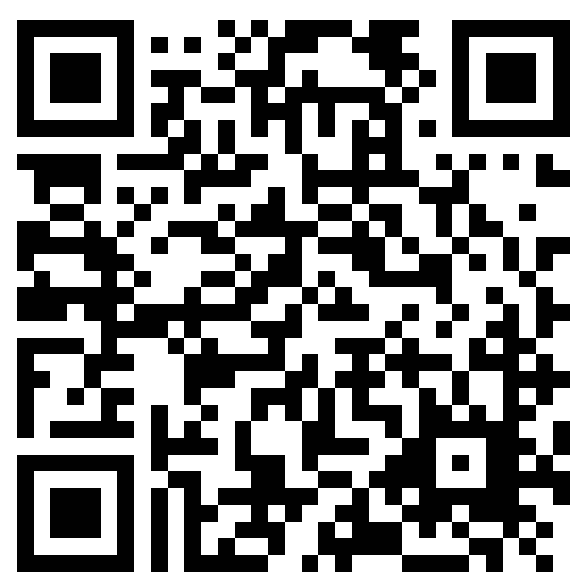

